\title{
Lattice Location of Mg in GaN: A Fresh Look at Doping Limitations
}

\author{
U. Wahl, ${ }^{1, *}$ L. M. Amorim,${ }^{2}$ V. Augustyns,${ }^{2}$ A. Costa, ${ }^{1}$ E. David-Bosne, ${ }^{1}$ T. A. L. Lima, ${ }^{2}$ G. Lippertz, ${ }^{2}$ \\ J. G. Correia, ${ }^{1}$ M. R. da Silva, ${ }^{3}$ M. J. Kappers, ${ }^{4}$ K. Temst, ${ }^{2}$ A. Vantomme, ${ }^{2}$ and L. M. C. Pereira ${ }^{2}$ \\ ${ }^{1}$ Centro de Ciências e Tecnologias Nucleares, Instituto Superior Técnico, Universidade de Lisboa, \\ 2695-066 Bobadela, Portugal \\ ${ }^{2}$ KU Leuven, Instituut voor Kern- en Stralingsfysica, 3001 Leuven, Belgium \\ ${ }^{3}$ Centro de Física Nuclear da Universidade de Lisboa, 1649-003 Lisboa, Portugal \\ ${ }^{4}$ Cambridge Centre for Gallium Nitride, University of Cambridge, Cambridge CB3 OFS, United Kingdom
}

(Received 14 November 2016; published 1 March 2017)

\begin{abstract}
Radioactive ${ }^{27} \mathrm{Mg}\left(t_{1 / 2}=9.5 \mathrm{~min}\right)$ was implanted into $\mathrm{GaN}$ of different doping types at CERN's ISOLDE facility and its lattice site determined via $\beta^{-}$emission channeling. Following implantations between room temperature and $800{ }^{\circ} \mathrm{C}$, the majority of ${ }^{27} \mathrm{Mg}$ occupies the substitutional $\mathrm{Ga}$ sites; however, below $350^{\circ} \mathrm{C}$ significant fractions were also found on interstitial positions $\sim 0.6 \AA$ from ideal octahedral sites. The interstitial fraction of $\mathrm{Mg}$ was correlated with the $\mathrm{GaN}$ doping character, being highest (up to $31 \%$ ) in samples doped $p$ type with $2 \times 10^{19} \mathrm{~cm}^{-3}$ stable $\mathrm{Mg}$ during epilayer growth, and lowest in Si-doped $n$-GaN, thus giving direct evidence for the amphoteric character of $\mathrm{Mg}$. Implanting above $350^{\circ} \mathrm{C}$ converts interstitial ${ }^{27} \mathrm{Mg}$ to substitutional $\mathrm{Ga}$ sites, which allows estimating the activation energy for migration of interstitial $\mathrm{Mg}$ as between 1.3 and $2.0 \mathrm{eV}$.
\end{abstract}

DOI: 10.1103/PhysRevLett.118.095501

Mg-doped $p$-type GaN is nowadays a core component of many optoelectronic devices which we find in our homes, e.g., light emitting diodes for solid state white lighting [1] or blue lasers [2]. Applications of $\mathrm{GaN}$ for power electronics, e.g., as high voltage transistors or power converters [3,4], also exist already but are less widespread; others, as in photovoltaics [5], may still emerge. Despite the technological maturity of $\mathrm{GaN}$, there are some basic properties related to its $p$-type doping that are still poorly understood and also limit the performance of devices. One such major problem is an inherent doping limit: once the $\mathrm{Mg}$ concentration in $\mathrm{GaN}$ surpasses $\sim 10^{19}-10^{20} \mathrm{~cm}^{-3}$, further introduction of Mg does not lead to an increase in the hole concentration; see, e.g., Ref. [6] and references therein. The electrical activation of $\mathrm{Mg}$ as a $p$-type dopant requires its incorporation on the substitutional $\mathrm{Ga}$ site $\mathrm{S}_{\mathrm{Ga}}\left(\mathrm{Mg}_{\mathrm{Ga}}\right)$, while $\mathrm{Mg}$ on other sites, e.g., interstitial $\mathrm{Mg}\left(\mathrm{Mg}_{i}\right)$, or $\mathrm{Mg}$ replacing $\mathrm{N}\left(\mathrm{Mg}_{\mathrm{N}}\right)$, should be electrically inactive or even exhibit donor character. In the earlier stages of GaN research it was suggested from ab initio density functional theory calculations by Neugebauer and Van de Walle [7,8] that "incorporation of the $\mathrm{Mg}$ atoms on the $\mathrm{N}$ site or in an interstitial configuration were found to be negligible." This view, however, was not shared by all theorists; e.g., Reboredo and Pantelides stated that "interstitial Mg plays a major role in limiting $p$-type doping" $[9,10]$. The failure of experimental methods in establishing the existence of interstitial $\mathrm{Mg}$ and investigating its properties probably contributed to the fact that in the following years many researchers adopted the opinion that the doping limitations at high $\mathrm{Mg}$ concentrations are, in addition to passivation by $\mathrm{H}$ $[8,11]$, mostly a consequence of native defects with donor character, in particular $\mathrm{N}$ vacancies $V_{\mathrm{N}}$, either in their isolated form $[12,13]$ or in $\mathrm{Mg}_{\mathrm{Ga}}-V_{\mathrm{N}}$ complexes with $\mathrm{Mg}[14,15]$.

Recently, this controversial discussion was revived by the results of hybrid density functional calculations of Miceli and Pasquarello [16], who concluded that "...the amphoteric nature of the $\mathrm{Mg}$ impurity is critical to explain the dropoff in the hole density observed experimentally": once the doping limit has been reached, additional $\mathrm{Mg}$ atoms are not incorporated on substitutional Ga sites any more but on interstitial sites where they form compensating double donors, thus pinning the Fermi level. The reader is referred to Ref. [16] for a more detailed discussion of several arguments that support this theory from the viewpoint of electrical and optical characterization methods. Low formation energies for interstitial $\mathrm{Mg}_{i}$, if the Fermi level is located below midgap, were also theoretically predicted by Reshchikov et al. [17].

In contrast to the various refined but often contradictory theoretical models on the structural properties of Mg-related defects in $\mathrm{GaN}$, no experimental data on the $\mathrm{Mg}$ lattice sites exist so far. The often used ion beam lattice location technique of Rutherford backscattering spectrometry and channeling (RBS/C) is not applicable in this case since $\mathrm{Mg}$ is much lighter than the Ga host atoms. Alternative ion beam detection methods such as particleinduced x-ray emission or nuclear reaction analysis fail at the low concentrations of $\mathrm{Mg}$ dopants. Attempts to use extended $\mathrm{x}$-ray absorption fine structure for characterizing the distances from $\mathrm{Mg}$ atoms to their nearest neighbors were not successful since the $\mathrm{Mg} K$ x-ray absorption edge overlaps with the Ga $L$ edge [18]. 
In this Letter, we provide direct lattice location measurements for $\mathrm{Mg}$ in $\mathrm{GaN}$ using the $\beta^{-}$emission channeling (EC) technique. We find that the majority of ion-implanted $\mathrm{Mg}$ occupies substitutional Ga sites. However, we present also direct experimental proof for the existence of interstitial $\mathrm{Mg}_{i}$ on positions near the so-called octahedral sites and we show that its fraction depends on the GaN doping character, being enhanced in samples that were predoped $p$ type with stable $\mathrm{Mg}$, and suppressed in Si-doped $n$-GaN. We also give experimental estimates for the migration energy of interstitial $\mathrm{Mg}$, which are derived from its microscopic interaction with $\mathrm{Ga}$ vacancies.

The EC method allows probing the sites of radioactive isotopes in single-crystalline samples [19-21]. The radioactive probe atoms are implanted at low fluences and the emitted $\beta^{-}$particles are guided by the crystal potential. A two-dimensional position-sensitive detector (PSD) $[20,21]$ is used to measure the angle-dependent emission yield of electrons in the vicinity of major crystallographic directions, providing patterns which are characteristic for the probe atom lattice location in the sample. In the case of $\mathrm{Mg}$, the only radioactive isotope suitable for EC studies is the short-lived ${ }^{27} \mathrm{Mg}\left(t_{1 / 2}=9.45 \mathrm{~min}\right)$ which can be produced at CERN's ISOLDE on-line isotope separator facility by means of bombarding Ti targets with $1.4 \mathrm{GeV}$ protons, followed by resonant laser ionization and mass separation [22]. This isotope was recently applied with success in the emission channeling study of the Mg lattice location in AlN [23].

The GaN layers used were grown by metal-organic chemical vapor deposition at the University of Cambridge and based on $4.8 \mu \mathrm{m}$ thick wurtzite single-crystal $\mathrm{GaN}$ epilayers on (0001) sapphire. The first type of sample simply consisted of the not intentionally doped (NID) epilayer (NID-GaN), while for " $n$-GaN:Si" samples a $150 \mathrm{~nm}$ thick layer doped with $1 \times 10^{19} \mathrm{~cm}^{-3} \mathrm{Si}$ was deposited in addition. $\mathrm{Mg}$ predoped samples contained a $150 \mathrm{~nm}$ thick top layer doped during growth with $2 \times 10^{19} \mathrm{~cm}^{-3} \mathrm{Mg}$. However, while "GaN:Mg" samples were used as grown, " $p$-GaN:Mg" samples were annealed for $20 \mathrm{~min}$ at $800^{\circ} \mathrm{C}$ under nitrogen atmosphere in order to drive out $\mathrm{H}$ and electrically activate the $\mathrm{Mg}$ [24]. While no electrical characterization was performed for the $p-\mathrm{GaN}: \mathrm{Mg}$ used in this experiment, typical hole concentrations and Hall mobilities for samples produced using the same equipment under almost identical conditions are $1-2 \times 10^{17} \mathrm{~cm}^{-3}$ and $10-15 \mathrm{~cm}^{2} / \mathrm{V} \mathrm{s}$ [25].

The EC measurements were performed simultaneously with $50 \mathrm{keV}$ implantations into a $1 \mathrm{~mm}$ diameter beam spot using the on-line setup described in Ref. [26]. The resulting ${ }^{27} \mathrm{Mg}$ profiles are approximately Gaussian with a typical depth of $488 \pm 244 \AA$ A. Because of its short half-life of $9.45 \mathrm{~min}$, there is hardly any ${ }^{27} \mathrm{Mg}$ accumulation in the samples throughout the experiments, with peak concentrations remaining below $3 \times 10^{14} \mathrm{~cm}^{-3}$, while its decay product ${ }^{27} \mathrm{Al}$ is a stable isotope isoelectronic to $\mathrm{Ga}$.

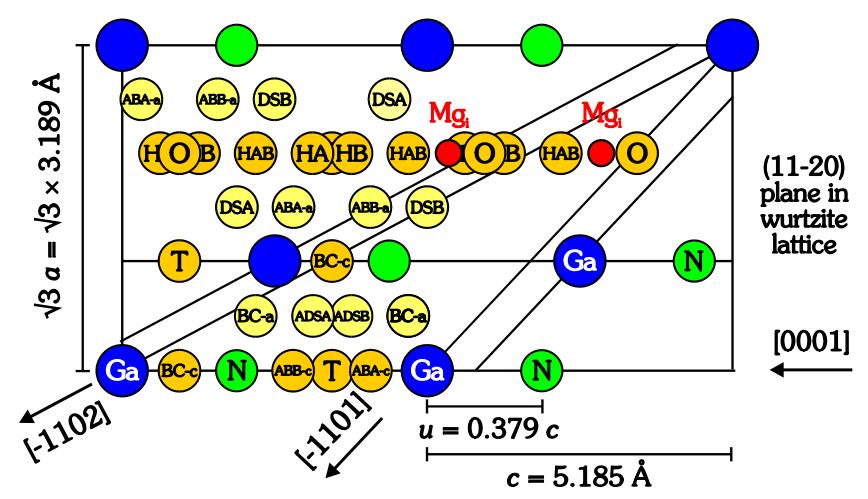

FIG. 1. (11-20) plane in the GaN wurtzite lattice, showing the $\mathrm{Ga}$ and $\mathrm{N}$ atom positions and the major interstitial sites that were investigated as possible lattice sites of $\mathrm{Mg}$. The result for the position of interstitial $\mathrm{Mg}_{i}$, which is shifted by $(0.60 \pm 0.14) \AA$ from the ideal octahedral $\mathrm{O}$ via the HA towards the HAB sites, is indicated by the red circles.

However, each implanted $\mathrm{Mg}$ atom initially creates several hundred $\mathrm{Ga}$ and $\mathrm{N}$ vacancies, which accumulate to some extent during the experiment according to the annealing history of the sample. In order to derive the fractions of ${ }^{27} \mathrm{Mg}$ on different lattice sites, the experimental $\beta^{-}$emission yields are fitted by theoretical patterns corresponding to ${ }^{27} \mathrm{Mg}$ emitter atoms residing on a combination of different lattice sites. Calculating the theoretical $\beta^{-}$patterns for $\mathrm{GaN}$ using the so-called "many-beam" formalism has been outlined in Refs. [27-29], while the fit procedure is described in Refs. [20,21,29]. The major lattice sites in $\mathrm{GaN}$ are shown in Fig. 1 while typical theoretical emission patterns for the major substitutional and interstitial sites are, e.g., given in Refs. $[23,28,29]$.

Figure 2(a) shows the $\beta^{-}$emission distribution around the [0001] surface direction from ${ }^{27} \mathrm{Mg}$ implanted at $200{ }^{\circ} \mathrm{C}$ into $p$-GaN:Mg at the very low beam current of $0.20 \mathrm{pA}$ into the $1 \mathrm{~mm}$ diameter beamspot, total fluence $1.1 \times 10^{11} \mathrm{~cm}^{-2}$, and measured with the $3 \times 3 \mathrm{~cm}^{2}$ PSD at $30 \mathrm{~cm}$ from the sample, resulting in an angular resolution of $\sigma \approx 0.1^{\circ}$. The fact that the [0001] direction and all major planes exhibit channeling effects proves that the majority of ${ }^{27} \mathrm{Mg}$ probes are aligned with the $c$ axis. However, comparing the experimental results to the theoretical pattern expected for $100 \%$ of ${ }^{27} \mathrm{Mg}$ aligned with the $c$ axis [Fig. 2(c)], one recognizes that the set of [01-10] planes has a lower intensity in comparison to [11-20] planes. This is a consequence of a minority of probes occupying positions in the wide open interstitial region of the wurtzite lattice, such as $\mathrm{O}, \mathrm{HA}, \mathrm{HB}$, or $\mathrm{HAB}$ sites (cf. Fig. 1) since for those sites the (01-10) planes show blocking effects while the (11-20) planes keep the same anisotropy as for sites aligned with the $c$ axis [Fig. 2(d)]. Indeed, the best fit to this experimental pattern was obtained for $31 \%$ of $\mathrm{Mg}$ on interstitial sites and $72 \%$ aligned with the $c$ axis [Fig. 2(b)]. Since [0001] channeling patterns do not allow us to determine the probe atom sites along the $c$ axis, in order to pinpoint the location of ${ }^{27} \mathrm{Mg}$ high angular resolution 


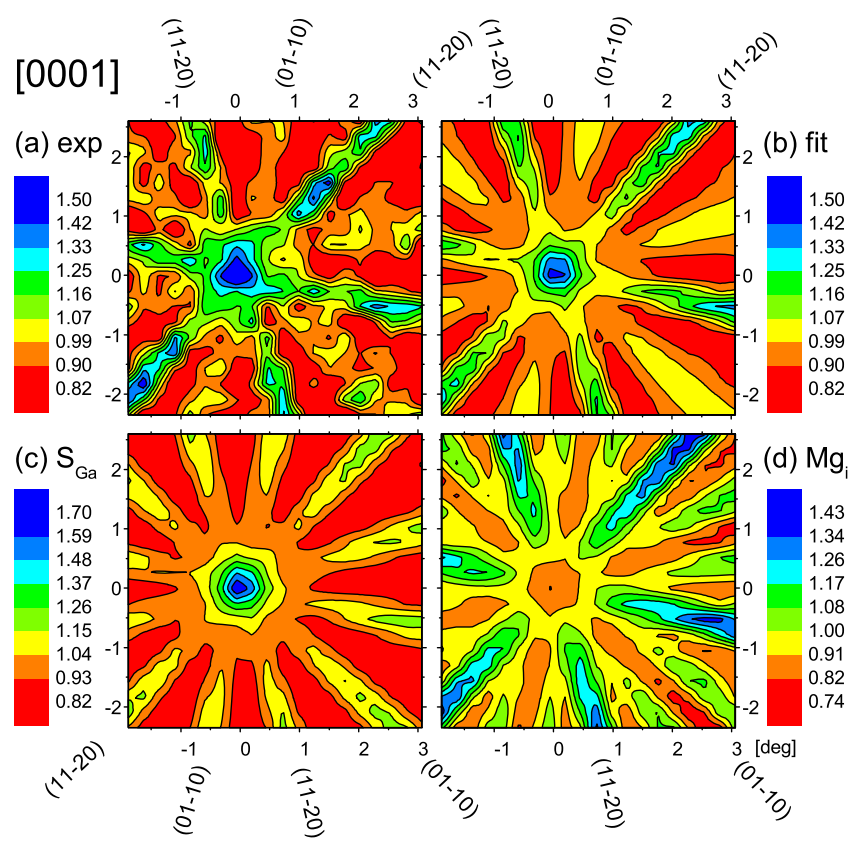

FIG. 2. (a) Experimental ${ }^{27} \mathrm{Mg} \beta^{-}$emission pattern around the [0001] axis of $p$-GaN:Mg during $200^{\circ} \mathrm{C}$ implantation at a beam current of $0.20 \mathrm{pA}$, in comparison to (b) the best fit of simulated patterns for $72 \%$ aligned with the $c$ axis, e.g., on $\mathrm{S}_{\mathrm{Ga}}$, and $31 \%$ on the $\mathrm{Mg}_{i}$ interstitial sites. The theoretical patterns for $\mathrm{S}_{\mathrm{Ga}}$ and $\mathrm{Mg}_{i}$ sites are shown in panels (c) and (d).

patterns with good statistics were measured around the [-1102], [-1101], and [-2113] directions [Figs. 3(d), 3(f), and 3(h)]. For that purpose, the PSD was placed at $60 \mathrm{~cm}$ from the sample, which increased the angular resolution to $\sigma \approx 0.05^{\circ}$, at the cost of a 4 times smaller solid angle. Hence, these measurements had to be performed at relatively high beam currents around $1.5-3 \mathrm{pA}$, with fluences of $1.5 \times 10^{12} \mathrm{~cm}^{-2}$ per pattern. As was immediately obvious, the experimental patterns could only be fitted well if the major fraction was located on $\mathrm{S}_{\mathrm{Ga}}$. Introducing a second site which was moved in steps of $0.05 \AA$ parallel to the $c$ axis showed that compared to the $\mathrm{S}_{\mathrm{Ga}}$ single-site fits, the $\chi^{2}$ always improves due to the additional degree of freedom provided by the fraction on the second site [Figs. 3(a)-3(c)]. However, the $\chi^{2}$ reaches minima at positions that are in between HA and HAB sites, displaced by about $+0.6 \AA$ from the ideal O sites, indicated as $\mathrm{Mg}_{i}$ in Fig. 1. The best fit of simulated patterns, corresponding to $74 \%$ on $\mathrm{S}_{\mathrm{Ga}}$ and $13 \%$ on these $\mathrm{Mg}_{i}$ sites, is displayed in Figs. 3(e), 3(g), and 3(i).

In Fig. 4 the fraction of ${ }^{27} \mathrm{Mg}$ on interstitial $\mathrm{Mg}_{i}$ sites is plotted as a function of the implantation temperature for the four different doping types of $\mathrm{GaN}$, investigated at low and high implantation beam currents. For collecting these data, each sample was once oriented with the [0001] facing the detector and then not moved again, only varying the implantation temperature and current, thus assuring maximum reproducibility of emission patterns and good control of the implantation fluence. Samples were first measured

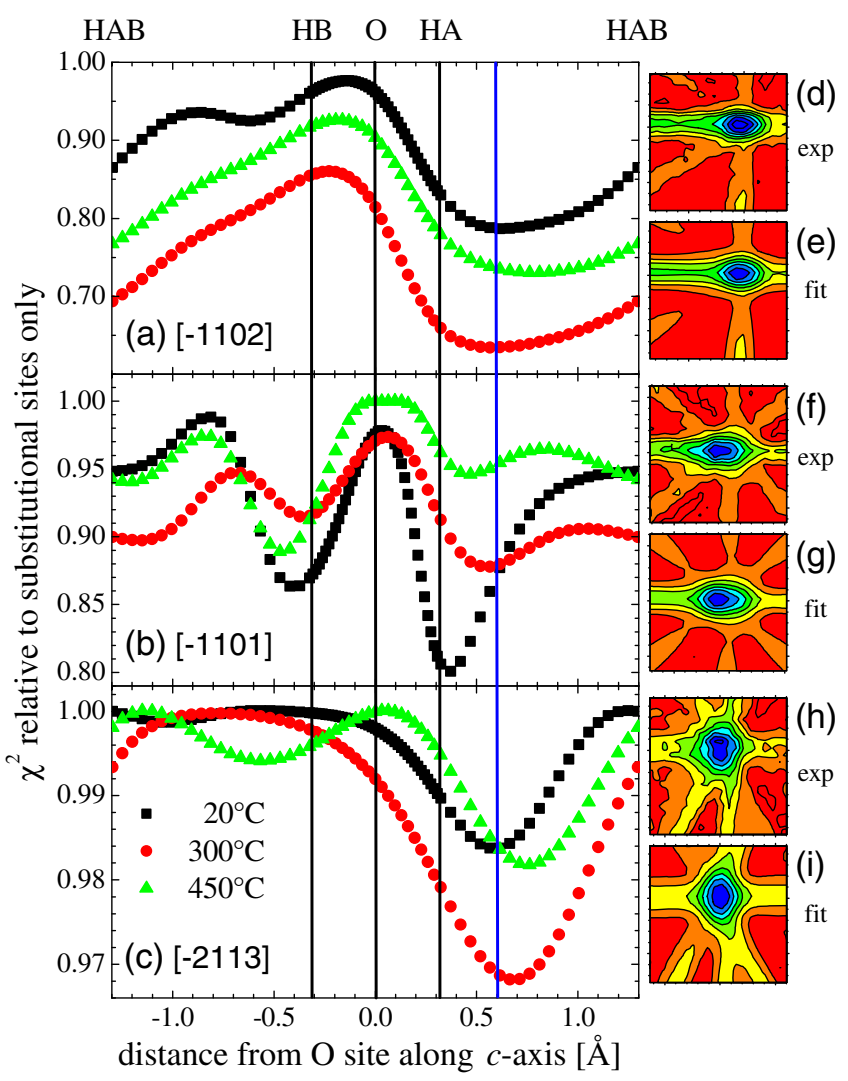

FIG. 3. (a)-(c) Reduced $\chi^{2}$ of the fits to the experimental [-1102], [-1101], and [-2113] patterns of $p$-GaN:Mg at 20, 300 and $450{ }^{\circ} \mathrm{C}$ as a function of displacement of the ${ }^{27} \mathrm{Mg}$ atoms from the ideal interstitial $\mathrm{O}$ sites parallel to the $c$ axis. Each data point corresponds to a two-site fit where the first site was kept fixed at $\mathrm{S}_{\mathrm{Ga}}$. The reduced $\chi^{2}$ was normalized to the one considering only $\mathrm{Mg}$ on $\mathrm{S}_{\mathrm{Ga}}$ sites. The adopted average value of the $\mathrm{Mg}_{i}$ displacement of $(+0.60 \pm 0.14) \AA$ is shown by the blue line. (d),(f),(h) are experimental patterns for the different axes obtained at $20^{\circ} \mathrm{C}$. (e),(g),(i) are best fits of simulated patterns, corresponding to $74 \%$ on $\mathrm{S}_{\mathrm{Ga}}$ and $13 \%$ on $\mathrm{Mg}_{i}$.

using beam currents of $0.20-0.27 \mathrm{pA}$ at 20 or $200^{\circ} \mathrm{C}$, followed by implantations and measurements at higher temperatures, then the beam current was increased to 1.4-3.0 pA and the procedure repeated, taking precautions that previously implanted activity does not alter the outcome of the experiment [29]. Several characteristics are obvious. For measurements within the same beam current series the interstitial ${ }^{27} \mathrm{Mg}$ fraction is clearly correlated with the doping type: ${ }^{27} \mathrm{Mg}_{i}$ is more prominent in $p$-GaN:Mg than in NID-GaN and lowest in $n-G a N: S i$. The second very clear characteristic is that for high implantation temperatures the interstitial fraction of ${ }^{27} \mathrm{Mg}$ is reduced, reaching in all cases values around $0 \%$ at $800^{\circ} \mathrm{C}$.

Third, for implantations at $200{ }^{\circ} \mathrm{C}$ into $p$-GaN:Mg, there is a clear and pronounced influence of the fluence visible: during the very first measurement $\left(0.20\right.$ pA, Fig. 2) $\mathrm{Mg}_{i}$ reached $31 \%$, dropping to $23 \%$ in a subsequent measurement at $0.27 \mathrm{pA}$; having finished the annealing sequence to $800^{\circ} \mathrm{C}$ 


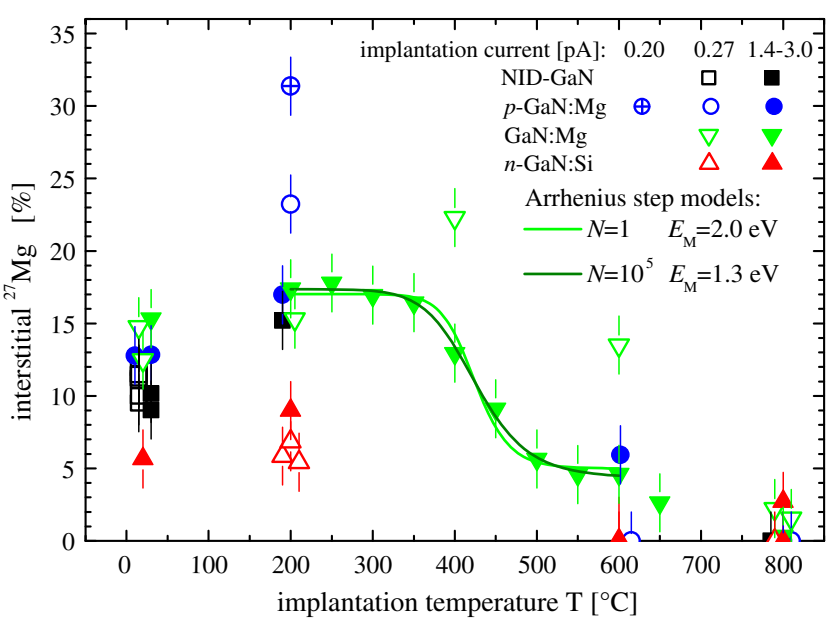

FIG. 4. Interstitial fractions of ${ }^{27} \mathrm{Mg}$ in the four different types of $\mathrm{GaN}$ samples as a function of the implantation temperature. Open symbols were implantations at low beam currents of 0.20-0.27 pA, while filled symbols were measured at 1.4$3.0 \mathrm{pA}$. The solid lines show the fractions using two Arrhenius models: $N$ is the assumed number of jumps required before encountering a $\mathrm{Ga}$ vacancy and $E_{M}$ is the activation energy for migration of interstitial $\mathrm{Mg}$.

(a temperature at which no more interstitial $\mathrm{Mg}$ was found), re-implanting at $200{ }^{\circ} \mathrm{C}$ with $1.4 \mathrm{pA}$ resulted in $17 \% \mathrm{Mg}_{i}$ only. Remarkably, in the case of $n-\mathrm{GaN}: \mathrm{Si}$, this trend is reversed: for the second sequence of measurements at higher implantation current the initially small fraction of $\mathrm{Mg}_{i}$ increased somewhat. In contrast, for NID-GaN the various data points for this sample at $20^{\circ} \mathrm{C}$ showed only a small decrease of the interstitial fraction from $12 \%$ to $9 \%$, while the accumulated beam charge increased from 70 to $4100 \mathrm{pC}$, corresponding to fluences of $5.5 \times 10^{10}$ to $3.2 \times 10^{12} \mathrm{~cm}^{-2}$. Overall, we attribute these fluence-related effects as caused by the introduction of implantation damage, which, as it accumulates, shifts the Fermi level of a sample towards midgap and also introduces more and more $\mathrm{Ga}$ vacancies. While the latter favors the formation of $\mathrm{Mg}_{\mathrm{Ga}}$ in all samples, the Fermi level shift is of minor consequences in NID-GaN but has opposite effects in $p$ - and $n$-type samples (decrease of $\mathrm{Mg}_{i}$ in $p$-GaN but an increase in $n$-GaN), which are overlaid on the influence of temperature and doping.

The GaN:Mg as-grown sample shows a particularly intriguing behavior at low-current implantation. While at $200{ }^{\circ} \mathrm{C}$ the ${ }^{27} \mathrm{Mg}$ interstitial fraction was identical to nid$\mathrm{GaN}$, it significantly increased at $400{ }^{\circ} \mathrm{C}$, then dropping again at higher temperatures. The initial increase might indicate a shift in the Fermi level of this sample towards the valence band as a consequence of the $400^{\circ} \mathrm{C}$ annealing causing acceptor activation of predoped stable $\mathrm{Mg}$, but such effects would need confirmation in further measurements.

The temperature dependence for high-current implantation into the GaN:Mg sample was used to estimate the migration energy $\left(E_{M}\right)$ of interstitial $\mathrm{Mg}_{i}$ applying two simple Arrhenius models. The models assume that $\mathrm{Mg}_{i}$ that remained interstitial following implantation starts to migrate due to its thermal energy and that it requires a certain number of jumps $N$ until it encounters a Ga vacancy during the lifetime of ${ }^{27} \mathrm{Mg}$, which will lead to the formation of $\mathrm{Mg}_{\mathrm{Ga}}$ (see Ref. [23] for details). Besides an attempt frequency $\nu_{0}$, for which we have taken $2 \times 10^{13} \mathrm{~Hz}$, corresponding to the $657 \mathrm{~cm}^{-1}$ local mode assigned to $\mathrm{Mg}$ in $\mathrm{GaN}$ [38], $N$ was assumed ranging from 1 to $10^{5}$, where $N=1$ represents the limiting case in which the $\mathrm{Mg}_{i}$ has a neighboring Ga vacancy, and $N=10^{5}$ is the upper limit when the diffusion-induced widening of the $\mathrm{Mg}_{i}$ profile becomes comparable to the implantation depth, which can be excluded since it would considerably deteriorate the channeling effects. According to the least square fits shown by the solid lines in Fig. 4, the migration energies are thus estimated between 2.0 and $1.3 \mathrm{eV}$, respectively. Theoretical predictions for $E_{M}[39,40]$ have suggested that the migration of $\mathrm{Mg}_{i}$ in planes perpendicular to the $c$ axis is much faster than along the $c$ axis, with $E_{M \perp}=$ $0.15 \mathrm{eV}$ and $E_{M \|}=0.68 \mathrm{eV}$, respectively. Our experimental estimates indicate a considerably higher $E_{M}$ value than these predictions. Several conflicting results on measuring the macroscopic diffusion coefficients of $\mathrm{Mg}$ in $\mathrm{GaN}$ have been reported in the literature, therefore suggesting that macroscopic diffusion of $\mathrm{Mg}$ is in fact trap limited. While Chang et al. state that during $1.25 \mathrm{~h}$ at $1060^{\circ} \mathrm{C}$ " no significant diffusion/segregation effects were observed" [41], Köhler et al. have determined an activation energy $E_{D}$ of $5 \mathrm{eV}$ in the temperature range $925-1050{ }^{\circ} \mathrm{C}$ [42], while Benzarti et al. concluded $1.9 \mathrm{eV}$ [43] and Pan and Chi $1.3 \mathrm{eV}$ only [44]. The value of $1.9 \mathrm{eV}$ would fit well with the microscopic migration energy estimated by us. However, Benzarti et al. based their analysis on only two measurements at $T=1090$ and $1130^{\circ} \mathrm{C}$, which at such high temperatures may be a too limited temperature region in order to derive trustworthy parameters for $D_{0}$ and $E_{D}$ in the exponential function.

Some immediate consequences of our findings on the interpretation of $\mathrm{GaN}$ doping with $\mathrm{Mg}$ are obvious. If $\mathrm{Mg}$ is introduced by means of ion implantation the damage caused by the implantation process has two characteristic effects. First, it provides the $\mathrm{Ga}$ vacancies which are necessary for $\mathrm{Mg}$ to be incorporated on substitutional $\mathrm{Ga}$ sites. Second, accumulation of damage causes a shift of the Fermi level towards midgap, which in the case of initially $p$-type $\mathrm{GaN}$ also results in an increase of substitutional $\mathrm{Mg}$. Our results, hence, indicate the potential use of ion-beam assisted growth methods for improving $\mathrm{Mg}$ incorporation at substitutional sites. With respect to direct ion implantation of $\mathrm{Mg}$, considerable success in achieving $p$-type doping was reported recently $[45,46]$, once suitable annealing procedures were established to overcome the negative effects of implantation damage. In contrast, the fact that the $\mathrm{Ga}$ vacancy creation process is absent when $\mathrm{GaN}$ is doped with $\mathrm{Mg}$ during epitaxial growth, suggests that in this case the excess $\mathrm{Mg}$ will rather enter the layer 
interstitially. At the typical temperatures for growth of GaN layers $\left(750-1100^{\circ} \mathrm{C}\right.$, depending on method), interstitial $\mathrm{Mg}$ will be quite mobile inside the deposited layers. If no $\mathrm{Ga}$ vacancies are available, diffusing $\mathrm{Mg}_{i}$ will also pair with other suitable defects, forming, e.g., $\mathrm{Mg}_{\mathrm{Ga}}-\mathrm{Mg}_{i}$ and similar complexes, as well as precipitates. Such a mechanism would cause $\mathrm{Mg}_{i}$-related complexes to contribute to the lack of electrical activation, particularly at high $\mathrm{Mg}$ concentrations, not only $\mathrm{H}$ or $V_{\mathrm{N}}$ related ones, which seems to be the widely accepted belief.

In summary, while $\mathrm{Mg}$ is found on substitutional Ga sites following ion implantation, we have also provided direct experimental evidence for interstitial $\mathrm{Mg}_{i}$ near octahedral sites. The amphoteric nature of $\mathrm{Mg}$ coupled to the Fermi level was proven by the fact that the abundancy of interstitial $\mathrm{Mg}_{i}$ is substantially increased in $p$-type GaN but suppressed in $n$-GaN. The activation energy for migration of $\mathrm{Mg}_{i}$ is estimated as $E_{M}=1.3-2.0 \mathrm{eV}$ from its conversion to substitutional $\mathrm{Mg}_{\mathrm{Ga}}$ above $350^{\circ} \mathrm{C}$.

We thank the ISOLDE Collaboration at CERN for developing and providing the ${ }^{27} \mathrm{Mg}$ beams. This work was funded by the Portuguese Foundation for Science and Technology (FCT) through project CERN/FIS-NUC/ 0004/2015 and the strategic project UID/Multi/04349/2013, the FWO Vlaanderen, and the KU Leuven (GOA/09/006, GOA/14/007, and BOF-STRT/14/002). The ISOLDE beam times were supported by the European Commission through the Horizon 2020 program (Grant No. 654002 ENSAR2).

*Corresponding author uwahl@ctn.tecnico.ulisboa.pt

[1] R. A. Oliver, Mater. Sci. Technol. 32, 737 (2016).

[2] M. T. Hardy, D. F. Feezell, S. P. Den Baars, and S. Nakamura, Mater. Today 14, 408 (2011).

[3] J. Baliga, Semicond. Sci. Technol. 28, 074011 (2013).

[4] M. J Scott, L. Fu, X. Zhang, J. Li, C. Yao, M. Sievers, and J. Wang, Semicond. Sci. Technol. 28, 074013 (2013).

[5] N. Lu and I. Ferguson, Semicond. Sci. Technol. 28, 074023 (2013).

[6] S. Brochen, J. Brault, S. Chenot, A. Dussaigne, M. Leroux, and B. Damilano, Appl. Phys. Lett. 103, 032102 (2013).

[7] J. Neugebauer and C. G. Van de Walle, Proc. Mater. Res. Soc. Symp. 395, 645 (1995).

[8] C. G. Van de Walle and J. Neugebauer, J. Appl. Phys. 95, 3851 (2004).

[9] F. A. Reboredo and S. T. Pantelides, Phys. Rev. Lett. 82, 1887 (1999).

[10] F. A. Reboredo and S. T. Pantelides, MRS Internet J. Nitride Semicond. Res. 4, 508 (1999).

[11] J. L. Lyons, A. Janotti, and C. G. Van de Walle, Phys. Rev. Lett. 108, 156403 (2012).

[12] Q. Yan, A. Janotti, M. Scheffler, and C. G. Van de Walle, Appl. Phys. Lett. 100, 142110 (2012).

[13] J. Buckeridge, C. R. A. Catlow, D. O. Scanlon, T. W. Keal, P. Sherwood, M. Miskufova, A. Walsh, S. M. Woodley, and A. A. Sokol, Phys. Rev. Lett. 114, 016405 (2015).
[14] S. Hautakangas, J. Oila, M. Alatalo, K. Saarinen, L. Liszkay, D. Seghier, and H. P. Gislason, Phys. Rev. Lett. 90, 137402 (2003).

[15] C. D. Latham, R. Jones, S. Öberg, R. M. Nieminen, and P. R. Briddon, Phys. Rev. B 68, 205209 (2003).

[16] G. Miceli and A. Pasquarello, Phys. Rev. B 93, 165207 (2016)

[17] M. A. Reshchikov, D. O. Demchenko, J. D. McNamara, S. Fernández-Garrido, and R. Calarco, Phys. Rev. B 90, 035207 (2014).

[18] K. Lawniczak-Jablonska, T. Suski, I. Gorczyca, N. Christensen, J. Libera, J. Kachniarz, P. Lagarde, R. Cortes, and I. Grzegory, Appl. Phys. A 75, 577 (2002).

[19] H. Hofsäss and G. Lindner, Phys. Rep. 201, 121 (1991).

[20] U. Wahl, Hyperfine Interact. 129, 349 (2000).

[21] U. Wahl, J. G. Correia, A. Czermak, S. Jahn, P. Jalocha, J. Marques, A. Rudge, F. Schopper, J. C. Soares, and A. Vantomme, Nucl. Instrum. Methods Phys. Res., Sect. A 524, 245 (2004).

[22] U. Köster, V. N. Fedoseyev, A. N. Andreyev, U. C. Bergmann, R. Catherall, J. Cederkäll, M. Dietrich, H. De Witte, D. V. Fedorov, L. Fraile et al., Nucl. Instrum. Methods Phys. Res., Sect. B 204, 347 (2003).

[23] L. M. Amorim, U. Wahl, L. Pereira, S. Decoster, D. J. Silva, M. R. da Silva, A. Gottberg, J. G. Correia, K. Temst, and A. Vantomme, Appl. Phys. Lett. 103, 262102 (2013).

[24] R. A. Oliver, F. C. -P. Massabuau, M. J. Kappers, W. A. Phillips, E. J. Thrush, C. C. Tartan, W. E. Blenkhorn, T. J. Badcock, P. Dawson, M. A. Hopkins, D. W. E. Allsopp, and C. J. Humphreys, Appl. Phys. Lett. 103, 141114 (2013).

[25] F. Karouta, M. J. Kappers, M. C. J. C. M. Krämer, and B. Jacobs, Electrochem. Solid-State Lett. 8, G170 (2005).

[26] M. R. Silva, U. Wahl, J. G. Correia, L. M. Amorim, and L. M. C. Pereira, Rev. Sci. Instrum. 84, 073506 (2013).

[27] U. Wahl, A. Vantomme, G. Langouche, J. Araujo, L. Peralta, and J. Correia, J. Appl. Phys. 88, 1319 (2000).

[28] B. De Vries, A. Vantomme, U. Wahl, J. G. Correia, J. P. Araújo, W. Lojkowski, D. Kolesnikov, and (ISOLDE Collaboration), J. Appl. Phys. 100, 023531 (2006).

[29] See Supplemental Material at http://link.aps.org/ supplemental/10.1103/PhysRevLett.118.095501, which includes Refs. [30-37], for details on the experiment, GaN many-beam calculations of theoretical emission patterns, and fit procedure.

[30] J. F. Ziegler, M. D. Ziegler, and J. P. Biersack, Nucl. Instrum. Methods Phys. Res., Sect. B 268, 1818 (2010).

[31] L. M. Peng, G. Ren, S. L. Dudarev, and M. J. Whelan, Acta Crystallogr. Sect. A 52, 257 (1996).

[32] H. Schulz and K. H. Thiemann, Solid State Commun. 23, 815 (1977).

[33] X. Xiong and S. C. Moss, J. Appl. Phys. 82, 2308 (1997).

[34] A. Yoshiasa, K. Koto, H. Maeda, and T. Ishii, Jpn. J. Appl. Phys. 36, 781 (1997).

[35] W. Paszkowicz, S. Podsiadło, and R. Minikayev, J. Alloys Compd. 382, 100 (2004).

[36] M. Schowalter, A. Rosenauer, J. T. Titantah, and D. Lamoen, Acta Crystallogr. Sect. A 65, 227 (2009).

[37] U. Wahl, E. Rita, J. G. Correia, E. Alves, and J. P. Araújo, Appl. Phys. Lett. 82, 1173 (2003).

[38] H. Harima, J. Phys. Condens. Matter 14, R967 (2002). 
[39] K. Harafuji, T. Tsuchiya, and K. Kawamura, Phys. Status Solidi (c) 0, 2240 (2003).

[40] K. Harafuji, T. Tsuchiya, and K. Kawamura, Jpn. J. Appl. Phys. 43, 522 (2004).

[41] Y. L. Chang, M. Ludowise, D. Lefforge, and B. Perez, Appl. Phys. Lett. 74, 688 (1999).

[42] K. Köhler, R. Gutt, J. Wiegert, and L. Kirste, J. Appl. Phys. 113, 073514 (2013).
[43] Z. Benzarti, I. Halidoua, Z. Bougrioua, T. Boufaden, and B. El Jani, J. Cryst. Growth 310, 3274 (2008).

[44] C. J. Pan and G. C. Chi, Solid State Electron. 43, 621 (1999).

[45] T. Oikawa, Y. Saijo, S. Kato, T. Mishima, and T. Nakamura, Nucl. Instrum. Methods Phys. Res., Sect. B 365, 168 (2015).

[46] T. J. Anderson, J. D. Greenlee, B. N. Feigelson, J. K. Hite, K. D. Hobart, and F. J. Kub, IEEE Trans. Semicond. Manuf. 29, 343 (2016). 